\title{
Costaceae endémicas del Perú
}

\author{
Blanca León ${ }^{1,2}$
}

${ }^{1}$ Museo de Historia Natural, Av. Arenales 1256, Aptdo. 14-0434, Lima 14, Perú

2 Plant Resources Center, University of Texas at Austin, Austin TX 78712 EE.UU.

blanca.leon@mail.utexas.edu

\section{Resumen}

La familia Costaceae es reconocida en el Perú por presentar tres géneros y 26 especies (Brako \& Zarucchi, 1993), todas ellas hierbas. En este trabajo reconocemos tres endemismos en dos géneros. Un género, Monocostus, es endémico. Las especies endémicas ocupan los bosques de la llanura amazónica y bosques premontanos húmedos, entre los 300 y 800 m de altitud. Ninguno de estos taxones se encuentra representado en un área natural protegida.

Palabras claves: Costaceae, Monocostus, Perú, endemismo, plantas endémicas.

\begin{abstract}
The Costaceae are represented in Peru by three genera and 26 species (Brako \& Zarucchi, 1993), all herbaceous plants. One genus, Monocostus, is endemic to Peru. Here we recognize three endemic species in two genera. The endemic species are found in Humid Amazonian Forests and Premontane Forests between 300 and $800 \mathrm{~m}$ elevation. None of the species have been reported to date from Peru's protected areas network.
\end{abstract}

Keywords: Costaceae, Monocostus, Peru, endemism, endemic plants.

\section{Costus asteranthus Maas \& H. Maas}

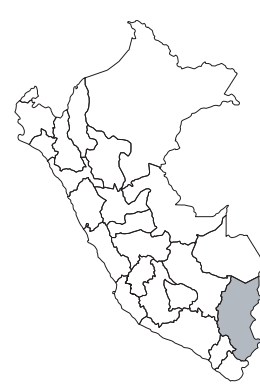

\section{CR, B1a}

Publicación: Notes Roy. Bot. Gard. Edinburgh 46(3): 307. 1990.

Colección tipo: P.J.M. Maas et al. 6086

Herbarios: MO, U.

Nombre común: Desconocido.

Registro departamental: PU.

Regiones Ecológicas: BMHP; 600—800 m.

SINANPE: Sin registro.

Herbarios peruanos: Ninguno.

Observaciones: Especie herbácea conocida, al parecer, sólo de la localidad tipo, en la cuenca del San Gabán. La deforestación podría ser un problema para la conservación de esta especie.

\section{Costus productus Gleason ex Maas var. productus}

\section{NT}

\section{Publicación:}

Colección tipo: E.P. Killip \& A.C. Smith 25317

Herbarios: NY, US.

Nombre común: Desconocido.

Registro departamental: CU, JU, PA, SM. Regiones Ecológicas: BHA; 300-700 m. SINANPE: Sin registro.

Herbarios peruanos: Ninguno.

Observaciones: Taxón herbáceo conocido de varias localidades en la Amazonía peruana. Fue descrita de una planta recolectada en 1929, de la cuenca del Paucartambo. Otras poblaciones han sido registradas en los últimos años.

\section{Monocostus uniflorus (Poepp. ex Petersen) Maas}

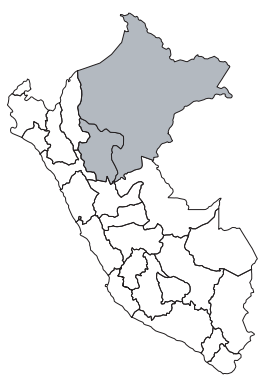

\section{EN, B1ab(iii)}

Publicación: Rev. Palaeobot. Palynol. 7(1): 37. 1968.

Colección tipo: G. Klug 4156

Herbarios: BM, F, GH, K, NY, S, U, US.

Nombre común: Desconocido.

Registro departamental: LO, SM.

Regiones Ecológicas: BHA; 300-330 m. SINANPE: Sin registro.

Herbarios peruanos: Ninguno.

Observaciones: Hierba descrita de una planta recolectada en 1935, en la cuenca del Huallaga. Esta especie fue recolectada en el siglo XIX, en Yurimaguas. Es la única representante de este género endémico al Perú. 